\title{
SENSITIVITY ANALYSIS OF THREE FLEXIBLE PAVEMENT DESIGN TECHNIQUES
}

\section{AUGUST I97| - NUMBER 14}

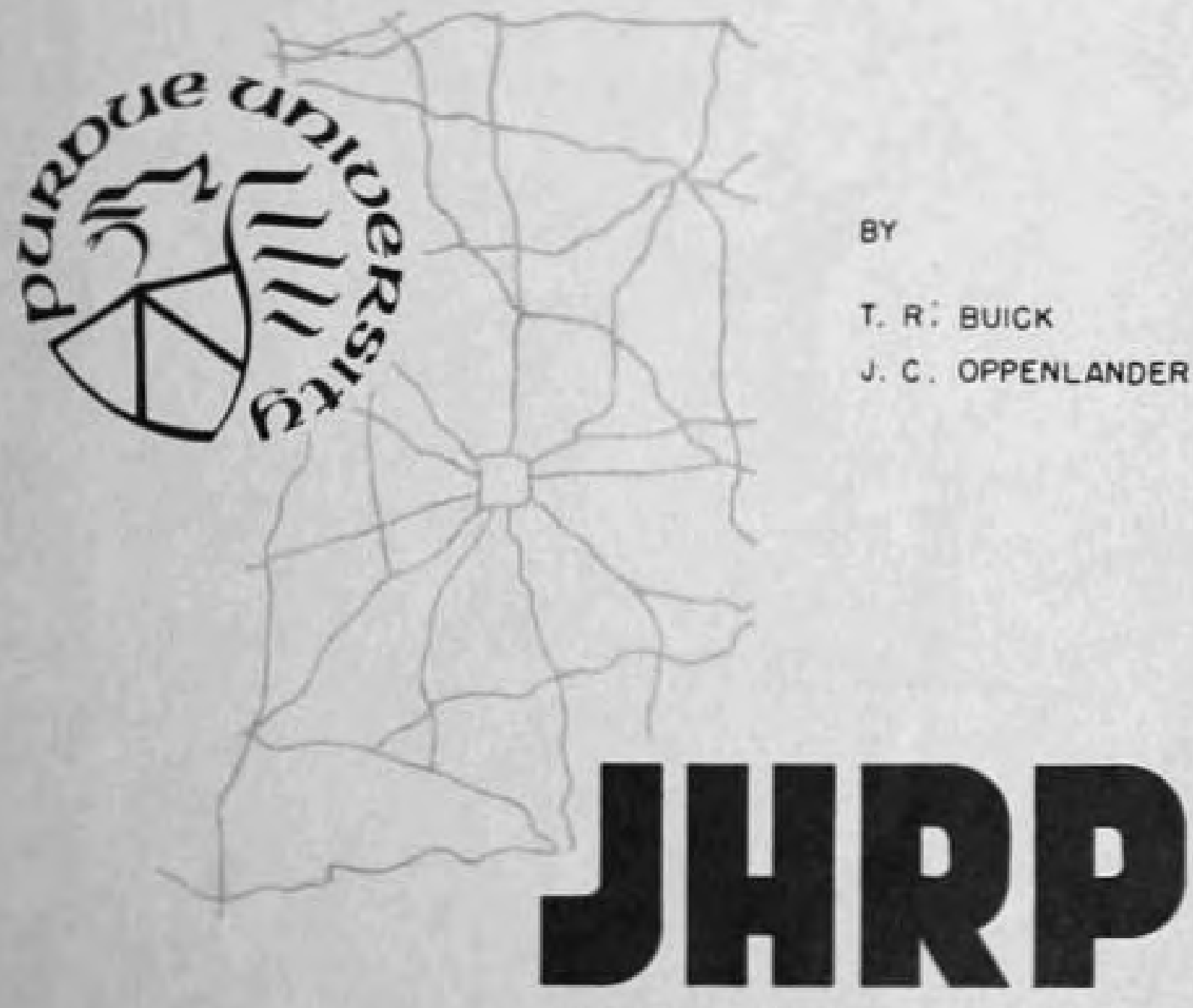

JOINT HIGHWAY RESEARCH PROJECT PuRDuE UNvEkerry and

wound stare neovas covvession 


\section{Technical Paper \\ SENSITIVITY ANALYSIS OF THREE FLEXIBLE \\ PAVEMENT DESIGU TECHNIQUES}

TO:

J. F. McLaughlin, Director
Joint Highway Research Project

FROM: H. L. Michae1, Associate Director Joint Highway Research Project.
August 11, 1971

File: 6-20-7

Project: $\quad C-36-52 \mathrm{G}$

The attached Technical Paper "Sensitivity Analysis of Three Flexible Pavement Design Techniques" has been authored by Messrs. T. R. Buick and J. C. Oppenlander. It is submitted for approval of presentation at and publication by the Third International Conference on the Structural Design of Asphalt Pavements.

The content of the paper is from the research report titled "Analysis and Synthesis of Highway Pavenent Design", J.H.R.P. Report No. 13, July 1968. The information in the paper has already been presented to the Board and accepted by that group.

The Paper is presented to the Board for action.

Respectfully submitted,

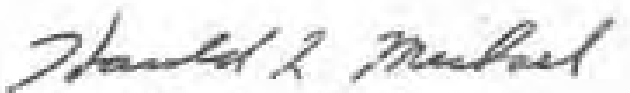

Harold L. Hichael

Assocíate Director

HLM : ms

cc: F. L. Ashbaucher

M. E. Harr

W. L. Dolch

R. H. Harrell.

M. B. Scott

W. H. Goetz

M. L. Hayes

W. T. Spencer

W. L. Grecco

R. D. Miles

J. A. Spooner

M. J. Gutzwiller

J. W. Miller

N. W. Steinkamp

G. K. Hallock

C. F. Scholer

H. R. J. Walsh

K. B. Woods

E. J. Yoder 


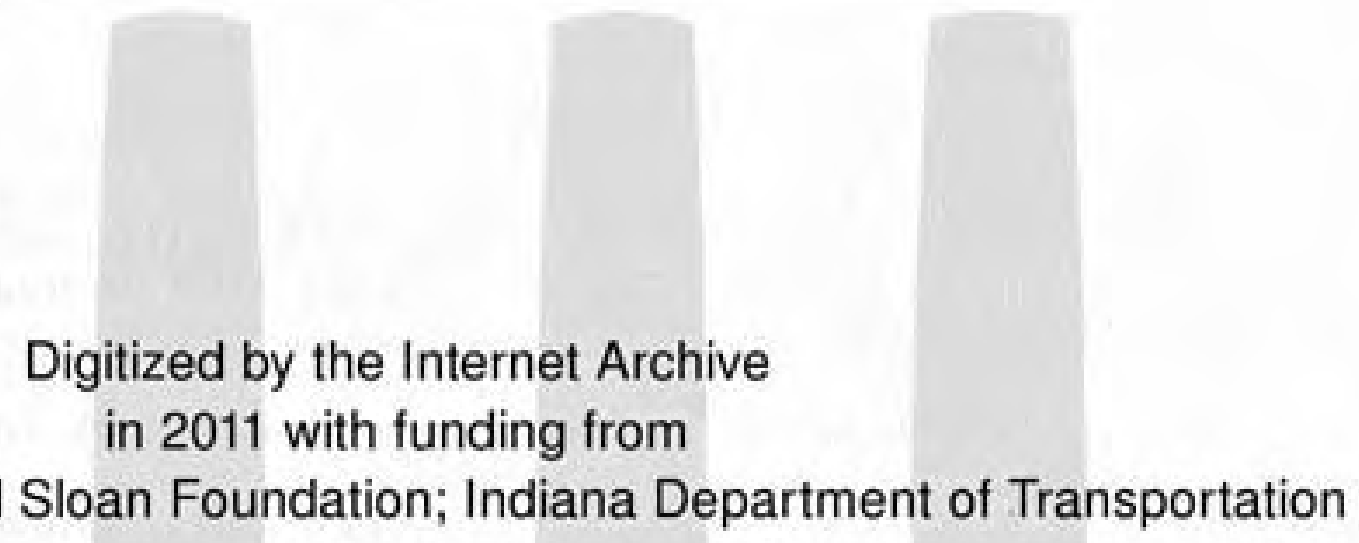

LYRASIS members and Sloan Foundation; Indiana Department of Transportation 
SENSITIVITY ANALYSIS OF THREE FLEXIBLE PAVEMENT DESIGN TECHNIQUES T. R. Buick" and J. C. Oppenlander ${ }^{* \text {. }}$

\section{ABSTRACT}

To better understand the axt and science of pavement design, three highway design techniques were studied to determine the relative effects of various design paramaters on pavement thickness. The analysis phase of this investigation consists of formulating each technique into a comprehensive mathematical or graphical thickness model. An evaluation of the influences on thickness of the major design factors vas accomplished by a sensitivity analysis with a theoretical and two practical, meazures of parameter importance.

The theoretical measure of parameter importance reveals considerable differences anong techniques as to the process of resolving design thicknesses and to the relative theoretical influence of various parameters that estimate the same major: design factors. However, the practical parameter importance measures, which account for variations in parameter values as well as the formulated parameter-thickness relationship, denonstrate a greater similarity in the importance of generic factors anong the design methods. For flexibie pavement design, traffic load and subgrade support are the more influential factors in the determination of pavement thickness.

Transportation Planner, Valley Area Traffic and Transportation Study, Tempe, Artzona.

* Professor and Chairman, Department of civil Engineering, University of vemont, Buxlington, Vernont. 


\section{INTRODUCTION}

The objective of flexible pavement design is the provision of an acceptable riding surface that can withstand the deteriorating effects of traffic and environment for the service life of the facility. This goal is considered an integral part of the total highway transportation program and is constantiy sought in quantitative measures. Various measurable paraneters are used to quantify the physical demands imposed on the pavement structure and the subjective desires of road users for a good riding surface. As a result, several design techniques have been developed to combine in a logical manner these design parameters to deternine the required pavement thickness.

Pavements designed for the same traffic load, soil support and environmental conditions, built of the same quality of materials and workmanship and expected to exhibit similar performance characteristics should be equal in thickness regardiess of the agency responsible for the design and construction. Such agreement is not the case because, in addition to the differences of the various design procedures available, nuch engineering experience and subjective judgment enter into the decisions required for resolving the design of paventent thicknesses.

Determining a satisfactory design thickness is inherently difficult, and the optimum design cannot be ascertained even though the major factors affecting paverrent thickness have been identified. Part of this problem is due to the uniqueness of the road structure and the conditions under which the facility must serve. A pavement is a thin narrow structure relative to its 
length, and is built at or near the ground surface. Thus, a single design, which is seldom changed over the contracted length of the roadvay, must satisfy a variety of subgrades and environmental influences. The heterogeneous nature of pavement building materials and their changing behavior with time and ambient conditions also contribute to the uncertainty of the pavement design process. While design is logically influenced by the performance expected of the pavement, methods of pavement evaluation and definttions of failure conditions have not always been clearly established for economical engineering purposes. The purpose of this research was to identify and examine the relative effects on design thickness of various design parameters which measure the subgrade support, traffic load, pavement material properties, environmental factors and performance criteria. ${ }^{2}$ Three flexible pavement design techniques, which are representative of present design practices, were analyzed to define the important set of pavement design variables considered in each design method. The relative importance of these design factors was determined in a sensitivity analysis that was developed to investigate the impact of changes in parameter values on the flexible pavement structure.

\section{PROCEDURE}

The procedure used in the analysis of selected flexible pavement design techniques is subdivideo into three phases: selection of pavement design methods, modeling of the design techniques, and sensitivity analysis. 
Selection of Pavement Design Methods

Because numerous techniques exist for the design of highway pavements, selection of several design methods was necessary to carry out this research investigation. Common usage of the technique, a rational approach to resolving the design thickness and the availability of literature pertaining to the design method were the main criteria used in selecting the three design methods for analysis. ${ }^{5}$ The flexible pavement design methods which best satisfy these criteria and which represent present design practices are: the AASHO Interim Guide for the Design of Flexible Pavoment Structures (AAsHo Plexible) ${ }^{1}$, the Corps of Engineers Flexible Pavement Design for Roads, Streets, Walks and Open Storage Areas (Corps Flexible) ${ }^{4}$ and the California Highway Department Stabilometer Design Method (California Stabilometer). 3

Modeling of the Design Technigues

After a thorough review of the literature pertaining to the selected pavement design methods, models of each design method were formulated to mathematically or graphically systematize the design-variable relationships for the puxpose of executing the sensitivity analysis. Design charts to facilitate the determination of the required pavement thickness and mathematical equations which are basic to the various design processes are available for each method chosen for this research investigation.

\section{Sensitivity Analysis}

The effects on thickness of the factors considered in pavement design were quantitatively evaluated in a sensivivity 
analysis. Applied to each design tecbnique investigated, the sensitivity analysis basically examined the change in design thickness produced by the various design parameters.

The underlying prenise of the sensitivity analysis phase of the procedure is that as the change in required pavement thickness produced by a design parameter becomes larger, the more important is that parameter in the design method. On this basis, the rate of change of thickness with respect to a particular parameter (quantified by the first partial derivative of the thickness with respect to that parameter) defines the theoretical measure of parameter importance, and the magnitude of the thickness change produced by compaxable parameter variations specifies the practical measure of parameter importance.

Theoretical Measure of Design Parameter Importance

The relative theoretical. importance was defined as the positive ratio of the partial derivative of a thickness with respect to a particular paraneter to the sum of the absolute values of the partial derivatives for all parameters. This determination is aymbolically written as:

$$
\operatorname{RPP}=100 \times\left|\frac{\partial T}{\partial P_{i}}\right|+\sum_{i=1}^{n} \mid \frac{\partial T}{\partial P_{i}}
$$

where $\quad$ RPP a relative percentage of a partial, $\begin{aligned}\left|\frac{\partial T}{\partial P_{i}}\right|= & \text { absolute value of the first partial derivative } \\ & \text { of the thiciness function }(T) \text { with respect to }\end{aligned}$ the design parameter $\left(P_{i}\right)$ and

$\sum_{i=1}^{n}\left|\frac{\partial T}{\partial P_{i}}\right|=$ surmation of the absolute values of all partial derivatives considered in the sensitivity analysis of a design method. 
The above relative percentage adequately determines the importance of each parameter as formulated in the thickness function, but this technique implicitIy assumes parameter variations to be numerically "small" and equal.

Measures of Practical Inportance of Design Parameters

The sizes of parameter variations encountered in actual. pavement design practice df,ffer considerably anong design parameters, and these increments of parameter change influence the range of design thicknesses required by each parameter. Therefore, the sensitivity analysis was expanded to examine the combined effects of both the mannez in which parameters were included in the thicknoss function and the actual parameter variations that occur. This combination zesulted in two measures of practical importance. One relative percentage measure of importance is mathematically shown as follows:

$$
\operatorname{RPTC}=100 \times\left|\frac{\partial T}{\partial P_{i}} \mathrm{dP}_{i}\right| \div \sum_{i=1}^{\mathrm{n}} \mid \frac{\partial T}{\partial P_{i}} \mathrm{aP}_{i}
$$

where RPIC = relative percentage of the thickreas change, $\left|\frac{\partial T}{\partial P_{i}} a_{i}\right|=$ absolute value of the product of the first paxtial dexivative of the thickness function (T) with respect to the design parameter $\left(\mathrm{P}_{i}\right)$ and the incremental parameter change $\left(\mathrm{dP}_{1}\right)$ and $\sum_{i=1}^{n}\left|\frac{\partial T}{\partial P_{i}} d P_{i}\right|=$ sumuation of the absolute values of all parameter products (partial derivative $x$ increment) considered in the sensitivity analysis of a design method. 
If appropriate $\left(\mathrm{dP}_{1}\right)$ increments are chosen as representative of actual parameter variations, then the absolute value of the term

$$
\left(\frac{\partial T}{\partial P_{i}} \mathrm{dP}_{i}\right)
$$

becomes a realistic measure of the change in thickness caused by a pavement design parameter. The portion of the total thickness change pxoduced by a perameter and calculated as a percentage if the total change provides a relative measure of design parameter importance to the totel design process rather then the formulated thickness function alone.

Because the validity of the relative percentage of the thickness change may be questionable as deviations from the mean parameter values become large, a second approach was devised as a corroborating measure of the practical importance of deaign parameters. If two different values are selected for the sane parameter, then two corresponding thicknesses are determined in the design of a flexible pavement. The difference between these two thicknesses is interpreted as the actual change in the design thickness produced by the parameter and its variation if the two parameter values are indicative of realistic paxameter variations normally encountered. Based on this uncomplicated concept, a thickness change caused by a variation in one parameter can be expressed as a percentage of the sum of all changes which are similarly calculated for each design parameter. This second measure of practical importance is summarized by the following equation: 


$$
\text { RPATC }=100 \times\left|\Delta \mathrm{T}_{\mathrm{P}_{i}}\right| \div \sum_{i=1}^{\mathrm{n}}\left|\Delta \mathrm{T}_{\mathrm{P}_{i}}\right|
$$

where $\quad$ RPATC $=$ relative percentage of the actual thickness change,

$$
\begin{aligned}
& \left|\Delta T_{P_{i}}\right|=\text { absolute change in thickness due to the }\left(P_{i}\right) \\
& \text { paraneter and } \\
& \sum_{i=1}^{n}\left|\Delta T_{P_{i}}\right|=\text { sum of all the absolute thickness changes } \\
& \text { produced by all paraneters in the design } \\
& \text { method under consideration. }
\end{aligned}
$$

Because very littie dffference was cbserved between the two measures of practical importance, only evaluations for the partial differential method are presented in this report of the sensitivity analysis of three flexible pavement design methods. The increment of parameter change was always selected to approximate one standard deviation of the 'population' for each design parameter.

\section{RESULTS}

The techniques of sensitivity analygis that were developed in the preceding section were applied to the AAsHO Flexible, the Corps of Engineers Flexible and the Callfornia Stabilometex design methods. Both theoretical and practical importance measures were quantified to demonstrate the significance of each design parameter in determining the resultant flexible pavenent thickness. 


\section{AASHO Interim Design Method for Rlexible Pavements}

To accomplish the sensitivity analysis of the AASHO design method, the following equation was developed to provide a mathematical expression for the nomograph presented in the AASHO Interim Design Method:

$$
\begin{aligned}
\log (W) & =9.36 \log (\mathrm{SN} * 1)-0.20 \\
& +\frac{\log \frac{c_{0}^{-p}}{c_{0}^{-1.5}}}{0.40+\frac{1094}{(\mathrm{SN}+1)^{5.19}}} \\
& +0.37756(\mathrm{SSV}-3.0) \\
& -0.97 \log (\mathrm{RP})
\end{aligned}
$$

where

$$
\begin{aligned}
S S V= & \text { soil support value } \\
R F= & \text { regional factor } \\
S N= & \text { weighted structural number } \\
C_{0}= & \text { initial serviceability inclex } \\
p= & \text { terminal serviceability incex and } \\
W= & \text { total number of equivalent } 18-\mathrm{k} i p \text { single- } \\
& \text { arle applications. }
\end{aligned}
$$

The sensitivity analysis of the AAsHO Flexible pavernent design method evaluated the relative importance of the soil support value, initial and terminal serviceability indices, equivalent $18-\mathrm{kip}$ single-axie load and regional factor as their significance affected the structural design of flexibla pavements. Although 
importance measures were calculated for many combinations of design parameter values, a sumnary of the sensitivity analysis is presented only for $1 i \mathrm{kely}$ conhinations in this report. Surmary plots of theoretical parameter importance are presented in Figures 1 and 2 for the upper and lower limits of soil support. The soil support value and the regional factor are theoretically the wost important design parameters in the formulated thickness function. In addition, stronger subgrades increase the importance of the soil support value and the regional factor and diminish the importance of the serviceability indices.

If a soil support value of 3.0 , a regional factor of 1.0 , a terminal serviceability inđex of 2,0 , an initial serviceability index of 2.0 , an initial serviceability index of 4.0 and a fourlane highway operating at a volume level of 1,200 passenger cars per hour per lane with 20 percent trucks are regarded as a typical design situation, then the approximate corresponding relative theoretical parameter importances are 32 percent for the soil support value, 36 percent for the ragional factor, 26 percent for the terminal serviceability index, and 6 percent for the initial serviceability index. The AAsHo traffic parameter assumes a negligible degree of theoretical importance. For increased volumes and magnitudes of traffic, the theoretical importance of the regional factor and the soil support value decreases while the importance of the serviceability indices increases. 
Practical measures of relative importance, which provide a more realistic determination of parametes inportance in the design process by accounting for the actual amount of variation that occurs in each factor, are illustrated in Figures 3 and 4 for the AASHO Flexible design method. Ranges of practical importance which represent various percentages of tirucks and traffic volumes are depicted by short horizontal lines and extended curves, respectively. For parameters of lesser tmportance, the short lines or extencled curves ars not distinguishable and a single line adequately represents the range of these practical measures. The five short lines identify parameter importance for a traffic stream composed of $10-, 20-, 30-, 40-$ end 70 -percent trucks, while the three extended linos describe practical importance for a hightray that carries the equivalent of $1200,1.500$, and 2000 passenger cars per hour per lane. Because greater traffic factor values imply higher volumes of traffic of: a larger percentage of trucics, the conditions represented by each line can easily be ascertained.

Because each plot: demonstrates the controling inportance of the AASHO traffic and subgrade parameiers, the soil support value and the total equivalent 18-kip single-axle load were concluded to be the two most. important parameters influencing the design objective. As the weight and frequency of vehicular traffic increases, the traffic parameter becomes less important, and the soil support value and the terminal serviceability index assume an increasing importance in the determination of flexible 
pavement thicknesses. If the sane typical design situation as appraised for theoretical parameter importance was again assumed for a pragmatic evaluation of the AASHO design factors, then the relative practical parameter importances are 33 percent for the traffic parameter, 37 percent for the soil support parameter, 8 percent for the regional factor, 20 percent for the terminal. serviceability index and 2 percent for the injtial serviceability index. While the AASHO traffic paraneter shows the most significant increase in practical importance as compered to the theoretical measure in which it had no influence, the regional factor exhibits the most prominent decrease.

Corps of Engineers Flexible Pavement Design Method for Streets and Road

Because the developinent of the Corps Flexible design method substantially depended upon empirical relationships, the design chart shown in Figure 5 was selected as the best available model for the sensitivity analysis. Mathematical equations which are basic to this design technique aid not completely describe the thickness function and, hence, could not be utilized to yield information of the precision which was obtalned by graphical interpretation of the design chart.

Since the Corps Flexible modol for the sensitivity analysis has only the two independent variables of California bearing ratio (CBR) value and design index, concurrent avaluation of the importance of the subgrade and the traffic parameters as well as the pavement component layer parameters vas not attempted. Therefore, theoretical and practical importance measures were 
determined only for individual CBR values relative to design index values. This assessment of CBR importance pertained to either subgrade, subbase, base or surface property influences on thickness, but nover to subgrade influences relative to pavenent structure influences.

If CBR values of 6 and 2, respectively, represent upper and lover strength measures of highway subgracies, then the evaluations of relative theoretical parameter importance are illustrated in Figures 6 and 7 for these two situations. A Calffornia bearing ratio of 40 was employed in pigure 8 to illustrate the theoretical importance of structural component materials relative to design indices.

For a frequently encountered design situation described by a subgrade CBR value of 4 , a design index of 5 and a subbase CBR value of 40 , the subgrade has an approximately 60 percent theoretical importance measure relative to the design index paraneter, and the subbase CBR parameter of 40 has an importance of about 16 percent relative to the Corps Flexible traffic factor. However, as traffic loads becone greater, the relative theoretical importance of the CBR parameter increases with a corresponding decrease in design index importance. A comparison among the plots of theoretical importance versus design index illustrates a decrease of importance for the supporting material parameter with increasing $\mathrm{CBR}$ values.

To predict representative variations in the Corps Flexible traffic parameter, the design index was assuned to be directly and linearly proportional to the California Stabilometer traffic 
parameter. Thus, readily determined variations in the California Stabilometex traffic index were translated into similar approximate variations of the Corps Fiexible design index parameter. This method of eatimating Corps Flexible design index variations does not enable average daily traffic or percentage trucks to directly influence the increments of change; consequently, ranges of practical importance do not occur for a given design index.

Because the practical importances of the design parameters were nearly ifentical for both the 'portions of the total differential' and the 'relative thickness changes' approaches, only values calculated by the former method are shown in Figures 9 and 10 for subgrade CBR values of 6 and 2, respectively. In addition, practical measures of the significance of subbase materials which are characterized by a CBR value of 40 are gumborized in Figure 11.

From an examination of the plots of practical importance for the Corps Flexihle method the CBR values chat represent the strengths of subgrade materials have the greatest influence on pavement thickness. As CBR values increase with the use of stronger supporting materials, only slicht changes in practical importance occur for the two design variables. However, when practical importance is evaluated for a CBR value of 40 and a design index of 6 , the traffic parameter is more important than the pavement material parameter. If the subgrade $C B R$ value is 4, the design index is 5 and the subbase CBR value is 40 , a typical example of the relative practical importance of the Corps Flexible parameters indicates that the subgrade parameter 
has an 85 percent rating relative to the design index and that the subbase parameter has a 55 percent practical importance measure relative to the traffic parameter. For the assumptions made in evaluating practical importance, the California bearing ratio paxameter has the greatest influence on thicknesses derermined by the Coxps Flexible design process.

California Division of Highways Stabilometer Design Method for Flexible Pavements

Further development of a thikckness Eunction model for use in sensitivity analysis of the California Stabilometer design technique was not necessary because the Iollowing design equation expresses the total design variahie relationships to the degree of completeness required in this research:

$$
T=K^{i} \frac{(T I) \quad(90-R)}{5}
$$

where $\quad T=$ thickness (inches)

$$
\begin{aligned}
\mathrm{K}^{t}= & .080=\text { correlation constant } \\
\mathrm{TI}= & \text { traffic index } \\
\mathrm{R}= & \text { resistance value of the soil (pounds per square } \\
& \text { inch) and } \\
\mathrm{C}= & \text { cohesiometer value (pounds per square incin). }
\end{aligned}
$$

In the California stabilometer technique for the design of flexible pavements, the primary factors are traffic, subgrade and pavement composition which are described by the tratfic index, the resistance value and the cohesiometer value, respectively. 
The relative theoretical importance of each design parameter, as indicated by the first partial derivative of the thickness function, is illustrated in Figures 12 and 13, respectively, for high and low design resistance values of the subgrade soil. The traffic paraneter is the most important factor and accounts for relatively 84 percent of the instantaneous rates of thickness change produced by all the design parameters. The resistance value determines 15 percent of the rates of flexible pavement thickness changes, and the cohesiometer value is of minimal theoretical influence by accounting for less than 1 percent of the rates of change.

The same paraneter value combinations were also used in the evaluations of practical parameter importance as shown in Figures 14 and 15. This practical measure of importance indicates a remaxkable increase in the inportance of the cohesiometer value and a decrease in the importance of the traffic index as compared to the corresponding theoretical. measures of relative importance. This phenorenon reflects the influence of parameter variations on thickness determinations. Practical influences change only slightly for different cohesiometer values.

If the parameter combinations of resistance value of 20.0 psi, cohesiometer value of 400.0 psi and traffic index of 12.0 are regarded as average, then the resistance value appears to be the most important parameter by accounting for 45 percent of the possible thickness variations. The traffic index ranks a close second at 40-percent importance and is followed by the cohesiometer value which is of 15-percent importance in the California 
Stabiloneter destgn process. Bettex subctrades increase the relative importance of their ciescriptive paraneters, but higher cohesiometer values do not change the rejative practical importance of that parametex. The various curves of practical. importance are flat which indicates the parameter influences on thickness do not vary appreciably with different traffic loads.

\section{SURARRT AND CONCIUSNONS}

The AASHO Flexible, COrps of Engineers Flexible and California stabslometer design methods were analyzed to identify and exmine the relative effects on thickness of the various factors consiclered in these pavemont destgn processes. A modeling of the design technigue, a measure of relative theoretical. paraneter inportance and two measures of relative practical. parameter importance were enployed in the investigation of these rlezible pavenent design methods. Whila the design objective of an adecruate highway pavement to serve the imposed physical and subjective demands is comion to all pevenent design techniques, the Factors considered and their mannex of employment are particular to each design technique. Subgzade characteristins, traffic loads, pavernent material properties, environmental factors and performance criteria are generaliy regorcled as the prinary factors affecting flestble pavenent desic̣n.

After a model of each technique which was adequate for the sensitivley amalygla was somulated, a quantîtative evaluation of the theoretical fnfluences of major factors on thickness substantiates the limited simliarity anong flextble design 
techniques. While the Corps Flexible and California Stabilometer traffic parameters are of considerable theoretical importance to their respective design techniques, the AAsHo Flexible traffic parameter has a negligible influence in the formulated thickness function. A summarization of paraneter importance for each technique is presented in Table 1. Percont importance values shown are for the average design situation as defined for each design method. In general, graphical sumaries are presented in this paper for high and low subgrade strength conditions to illustrate the influence of their ranges of values on the various measures of theoretical and practical importance. Flowever, similar piots for average design conditions, which are the basis for the parameter importance summarized in Table 1 are available in the original report of this research investigation. ${ }^{2}$

Average practical measures of parameter importance are also shown in Table 1. These realistic neasures which account for parameter variations show a general agreement among design methods of the relative importance of the primary factors which influence pavement thickness. The traffic measures and the supporting solil parameters are ranked as the two most important: factors in practical importance, and pavement material properties rank third among the flexible design procedures. The sensitivity analysis of the physical and subjective factors affecting thiciness and expected pavement performance provides the design engineer with greater insight into the decision making process of accomplishing the structural design 
of flexible pavements. The effect of actual deviations associated with these parametor design values identifies those phases of the design process requiring closer attention and study and indicates those areas where design information is exceedingly precise.

\section{BIBLIOGRAPHY}

1. AASHO Committee on Design, AASHO Interim Guide for the Design of Flexible Pavement Structures, American Association of State Highway officials, 1961.

2. Buick, T. R., "Analysis and Synthesis of Highway Pavement Design," Joint Highway Research Project, Furdue University, Report No. 13, July 1968.

3. Hveen, F. N. and G. B. Sherman, "California Method for the Structural Design of Flexible Pavenents," Proceedings, International Conference on Structural Design of Asphalt Pavements, 1962 .

4. Rice, J. L., "An Evaluation of the Corps of Engineers Pavement Design Criteria Utilizing the Results Obtained from the AAsHo Road Tests," Technical Report No. 4-41, Corps of Engineers, Ohio River Division Laboratories, 1966.

5. Yoder, E. J., Principles of Pavement Design, John Viley \& Sons, Inc., New York, 1959. 


\section{AASHO FLEXIBLE DESIGN}

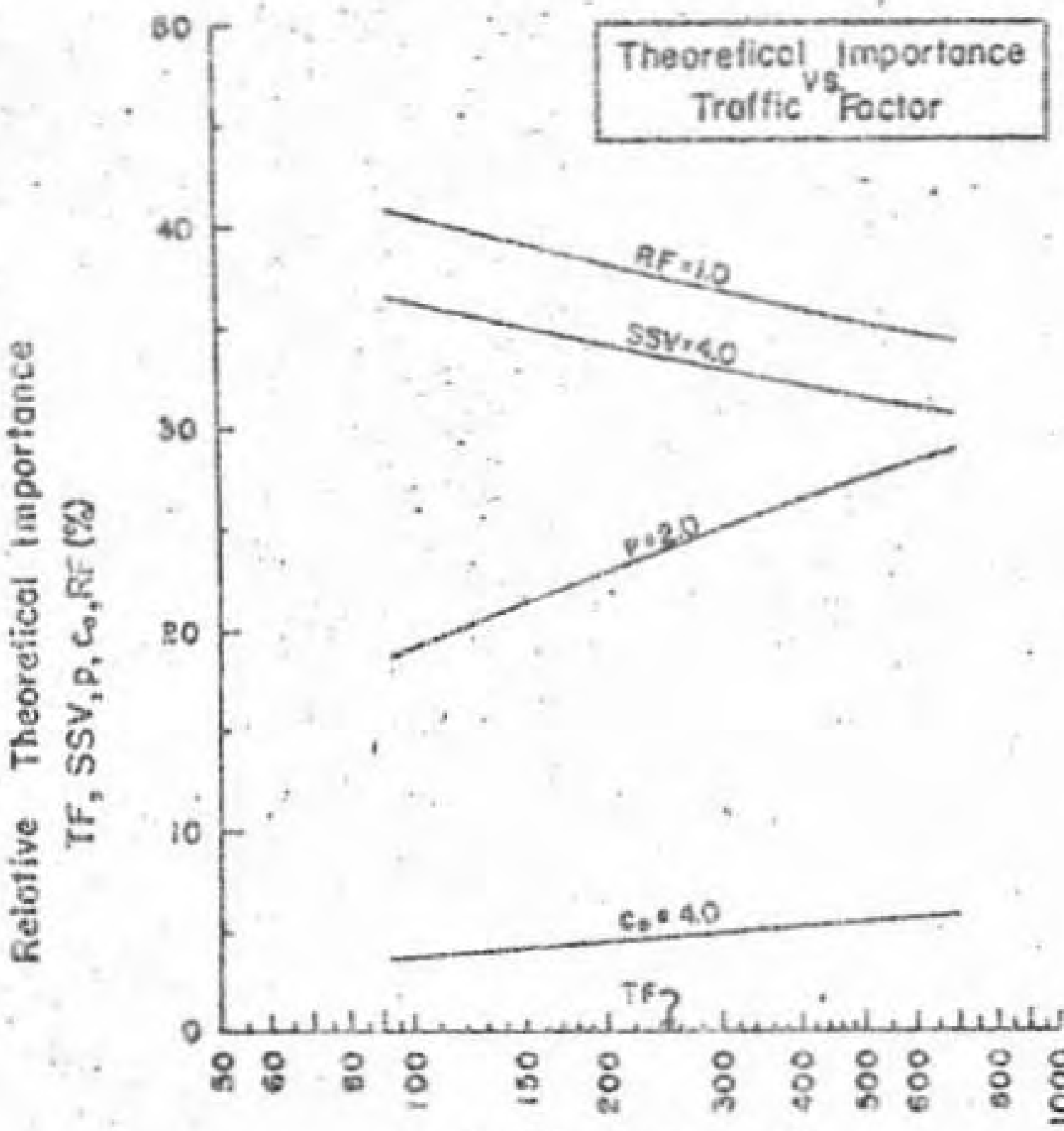

- Truffic Foctor $T F$

(squiv. doily $i 8^{x}$ single axle lood opplicotions)

Figure 1. Relative Theoratical Importanca of AASHO Flexible Design Poromeiss 


\section{AASHO FLEXIBLE DESIGN}

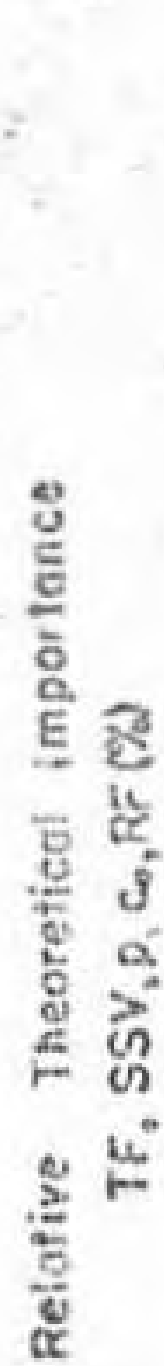

\section{0}

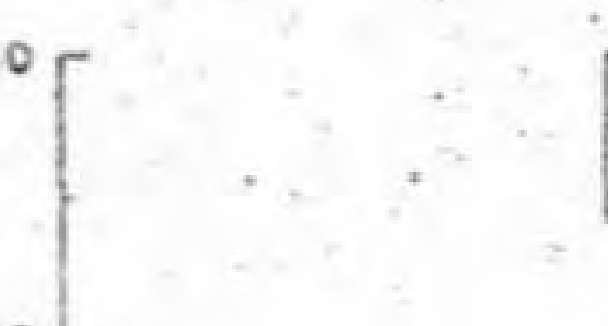

Theorefical importance Traffic ${ }^{\mathrm{vs}}$ Factor

40
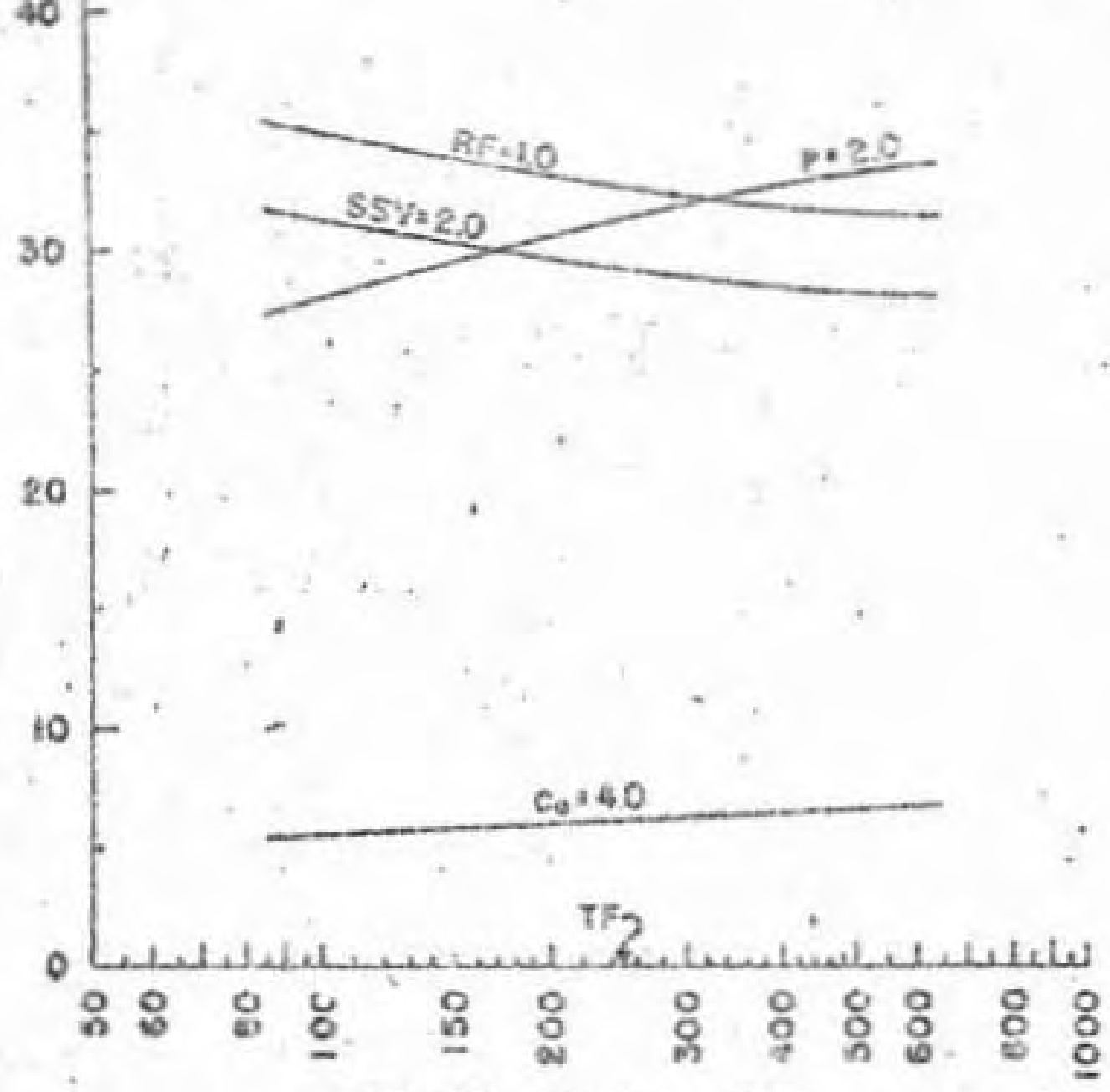

Trolfic Foctor TF

(equiv. daily $18^{k}$ sinple oxie lood opplications)

Figure 2. Rolative Theoretical importance of AASHO Flexible Desion Porometers 


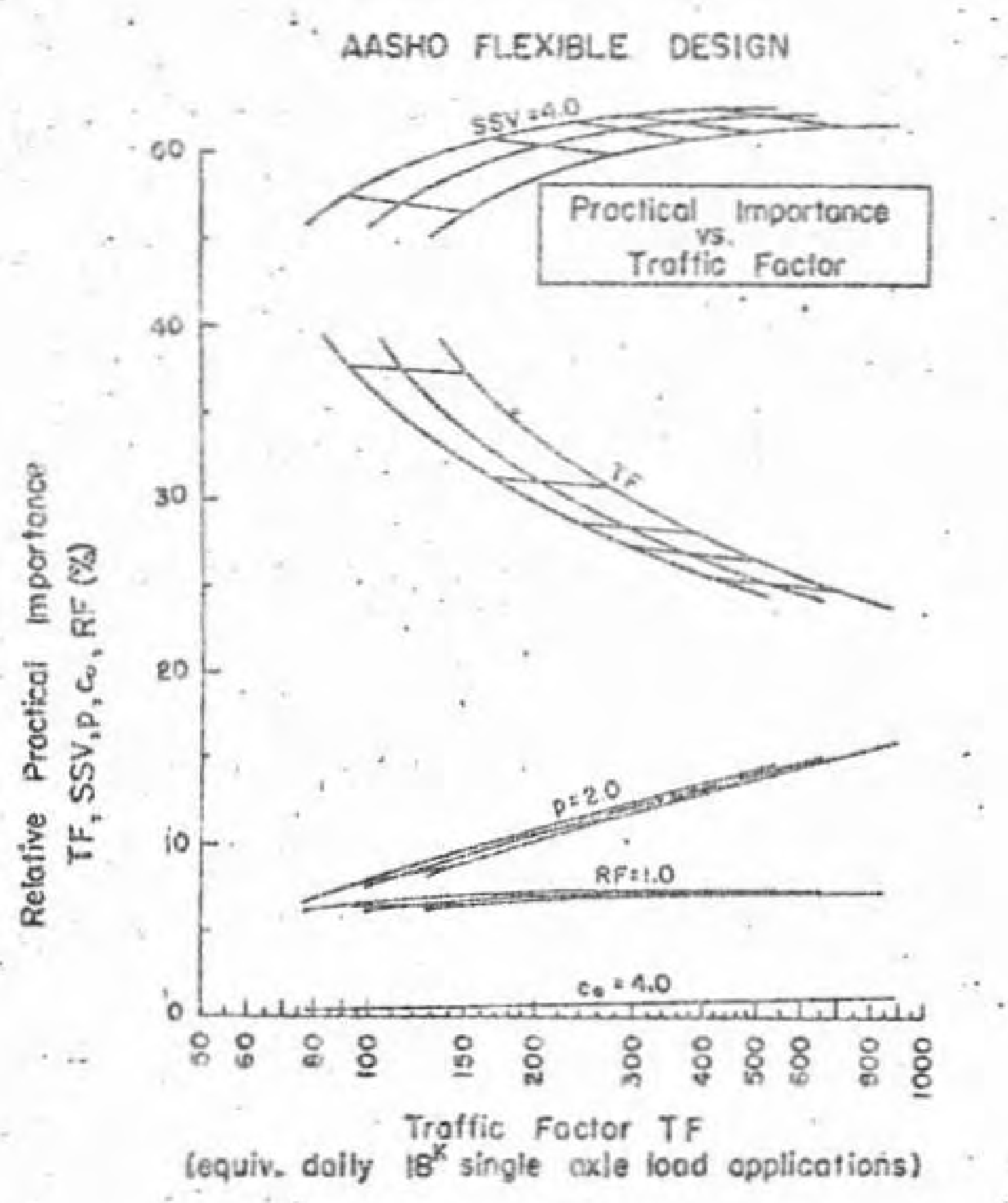

Figure 3. Relative Procticel Importance of AASHO Flexible Design Porometers 


\section{AASHO FLEXIBLE DESIGN}

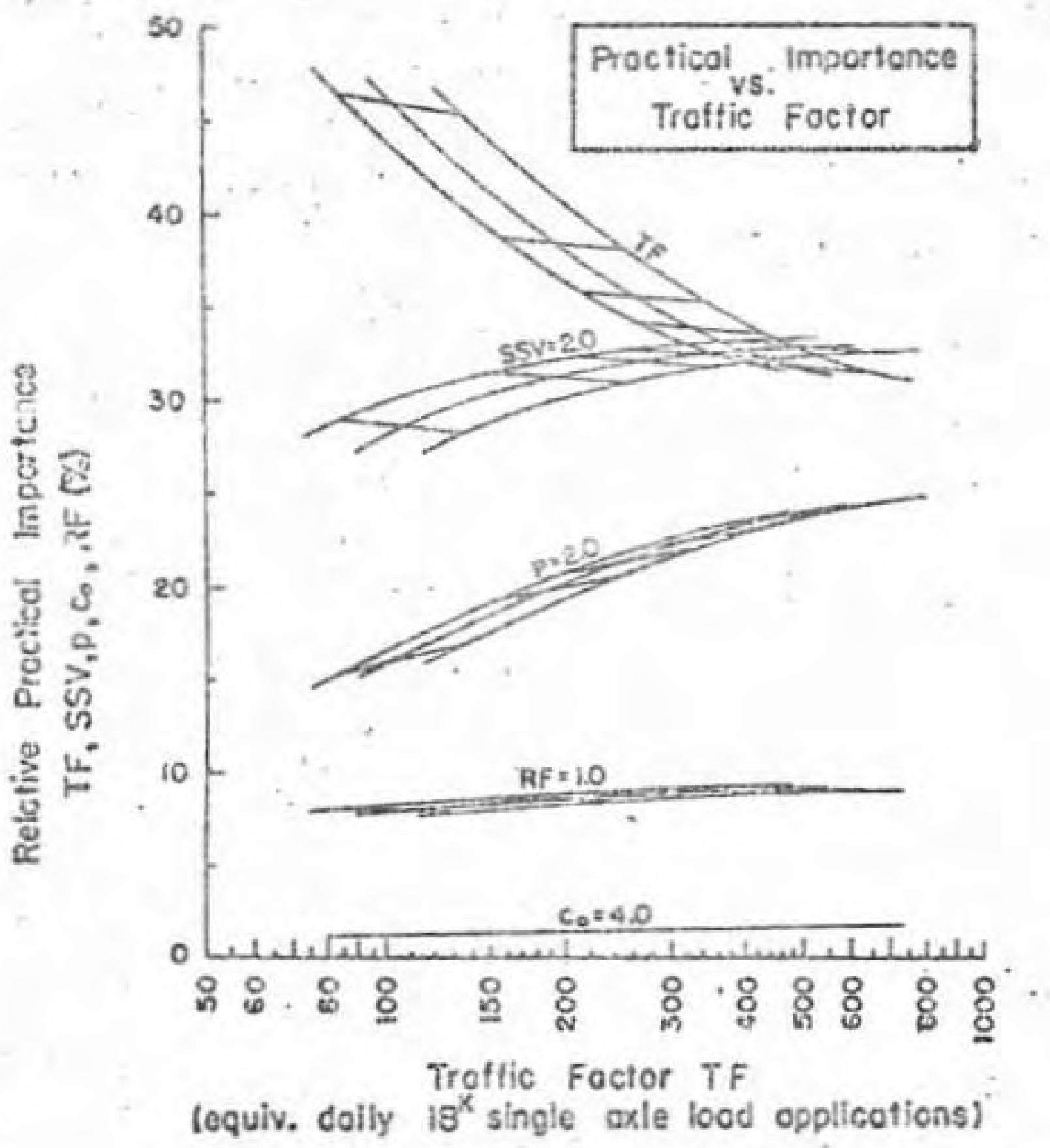

Figure 4. Relative Procticol Importance of $\therefore$ AASHO Flexiblo Dosign Poromaters 
Corps Flexible

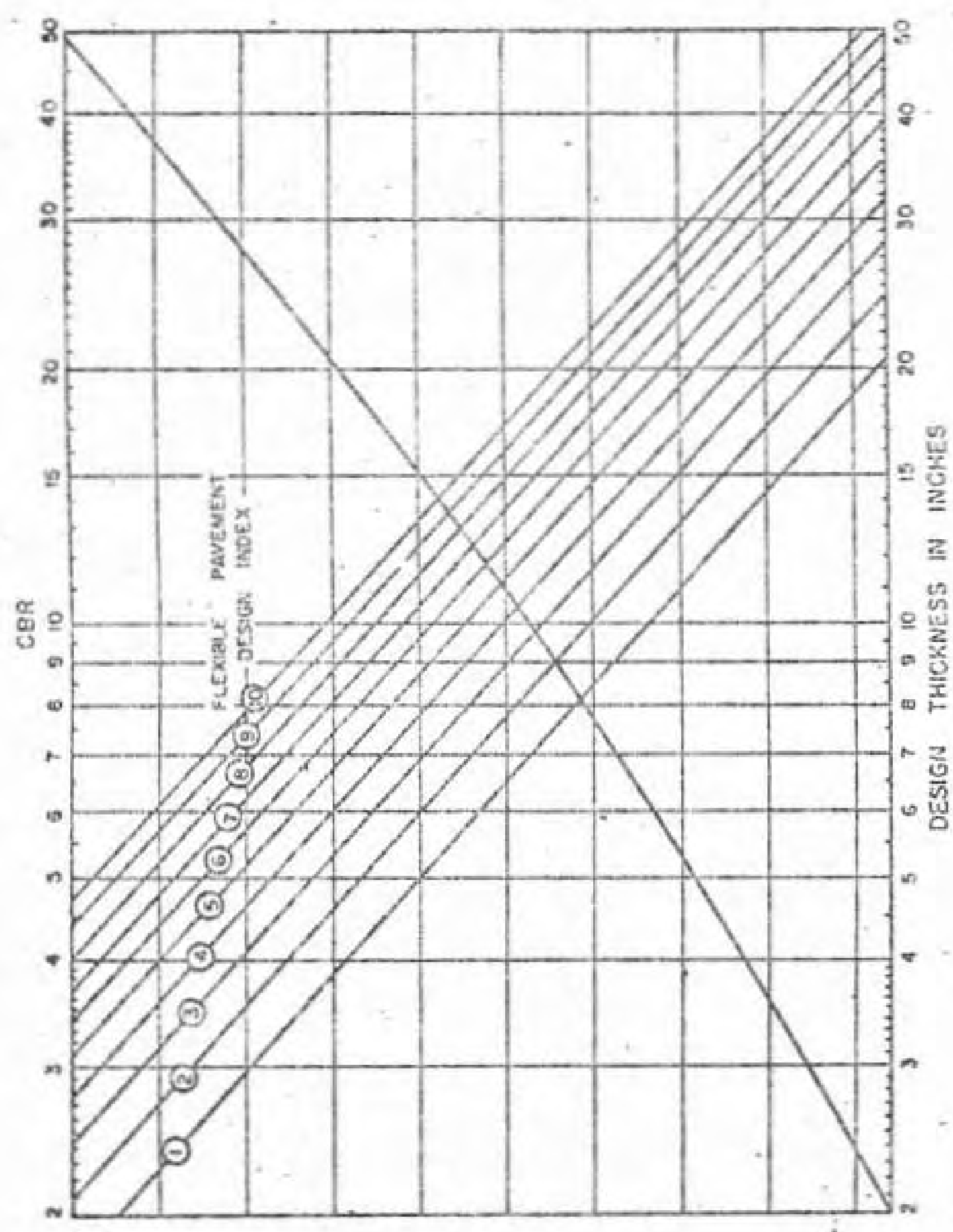

Figure 5. Corps Flexible Design Chart 


\section{CORPS FLEXIELE DESIGN}

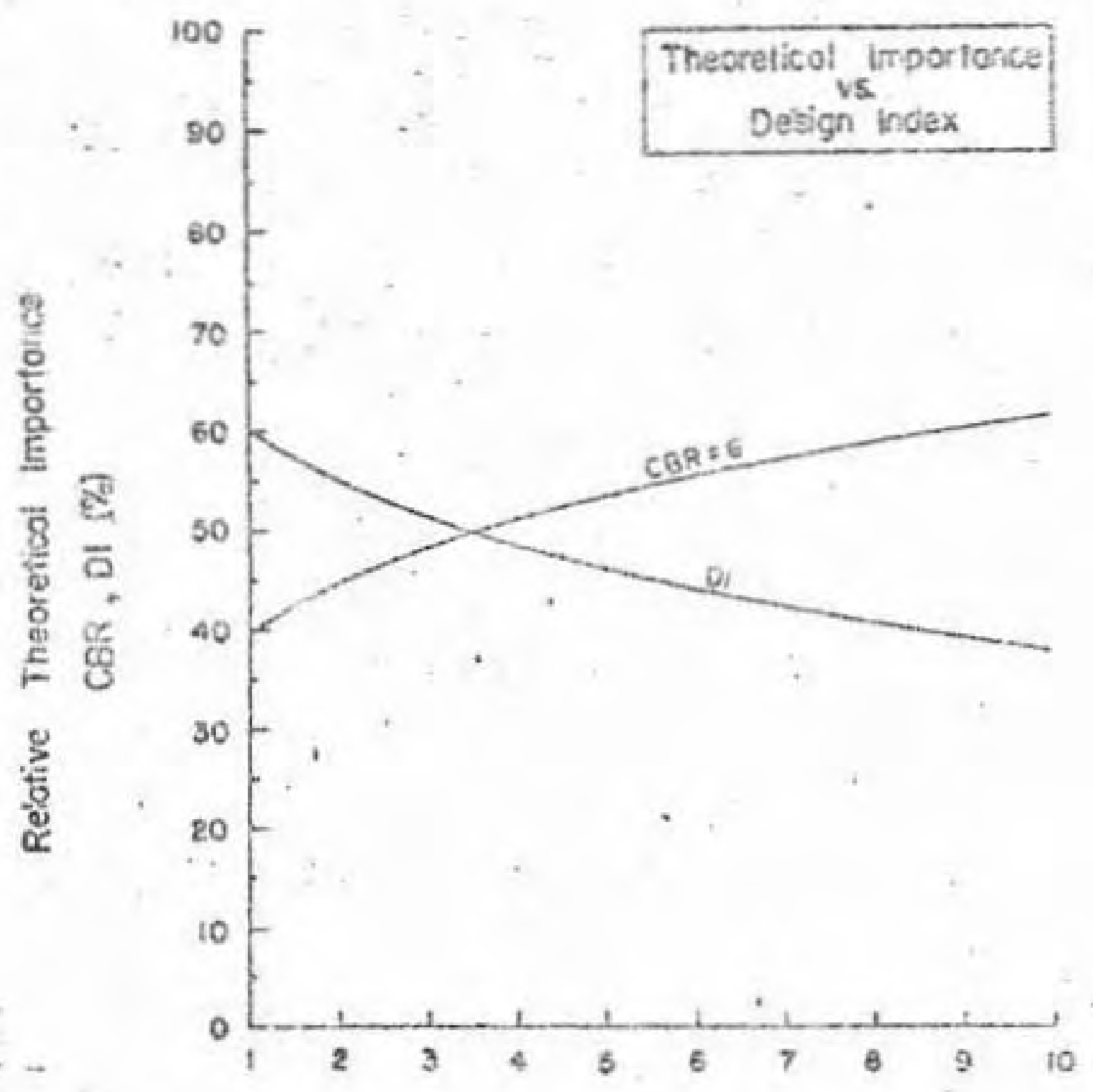

Design index Di

Figure 6. Relative Theoreficol importance of corps Flexibls Design Porometers 
CORPS FLEXIQLE DESIGN

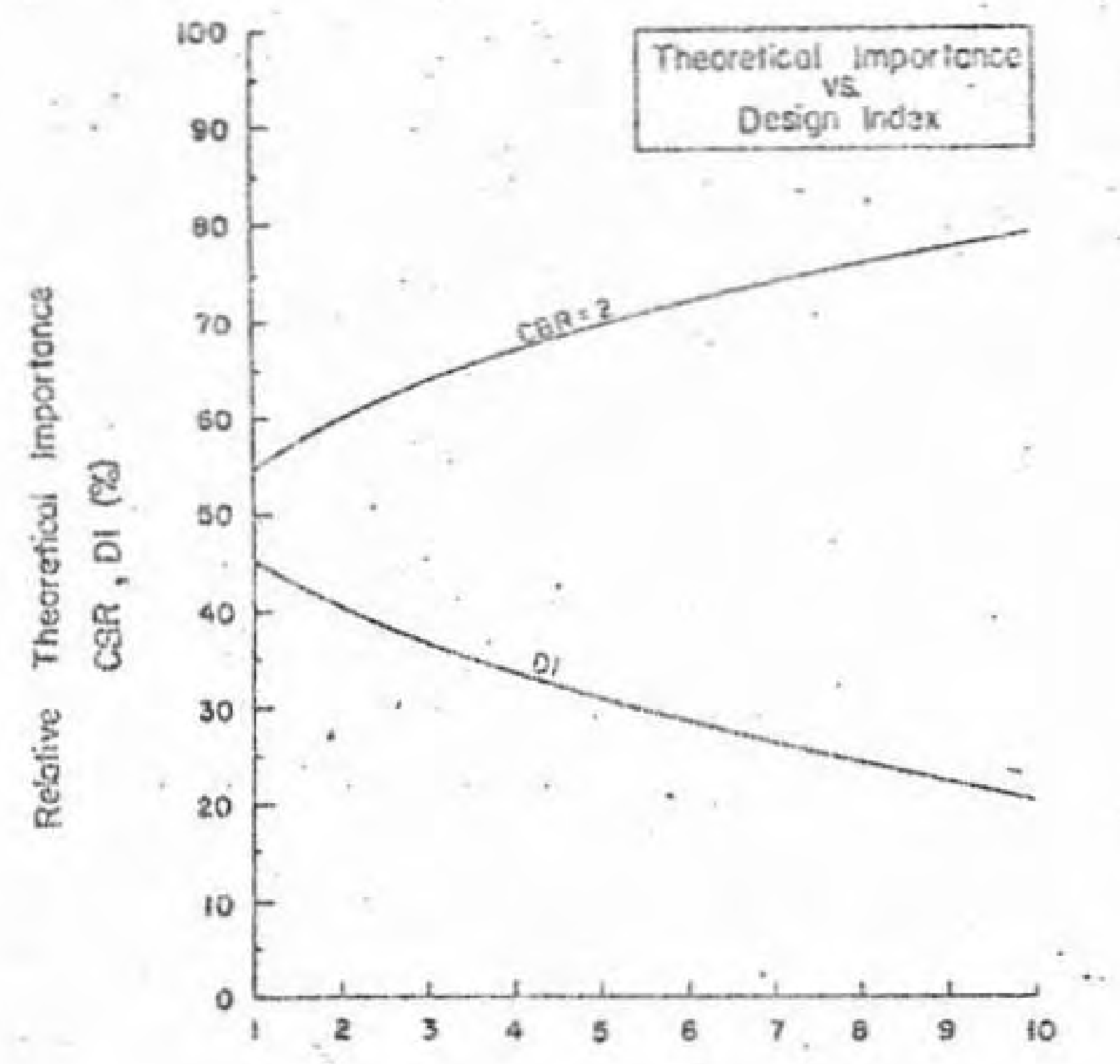

Design Indax OI

Figure 7. Relotive Theoretical importence of Corps Flexible Desigrs Porometars 
CORPS REXIBLE DESIGN

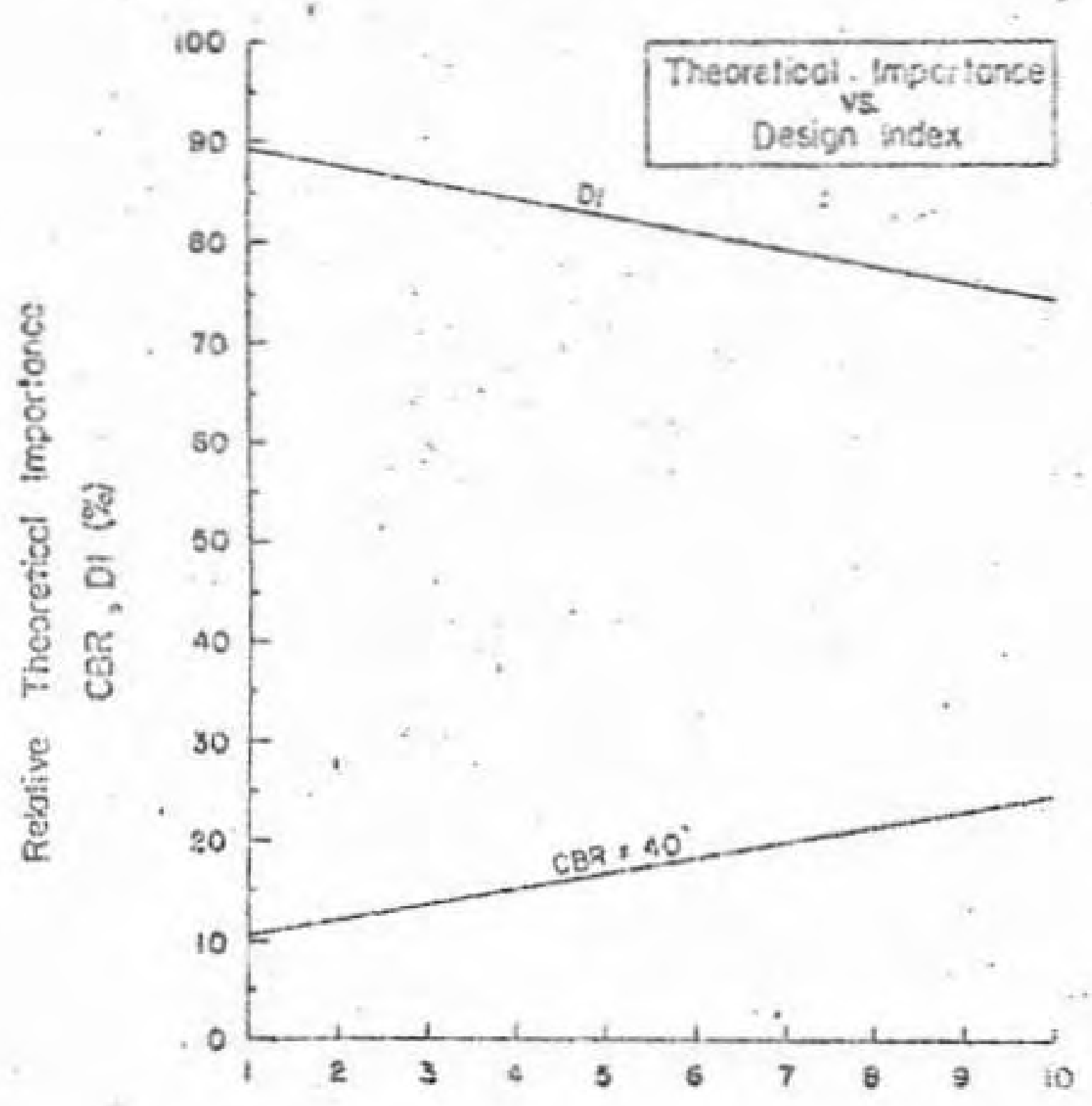

Design index DI

Figure 8. Relative Theoreficol importunce of Corps Flexible Design Poromaters 
CORPS FLEXIBLE DESIGN

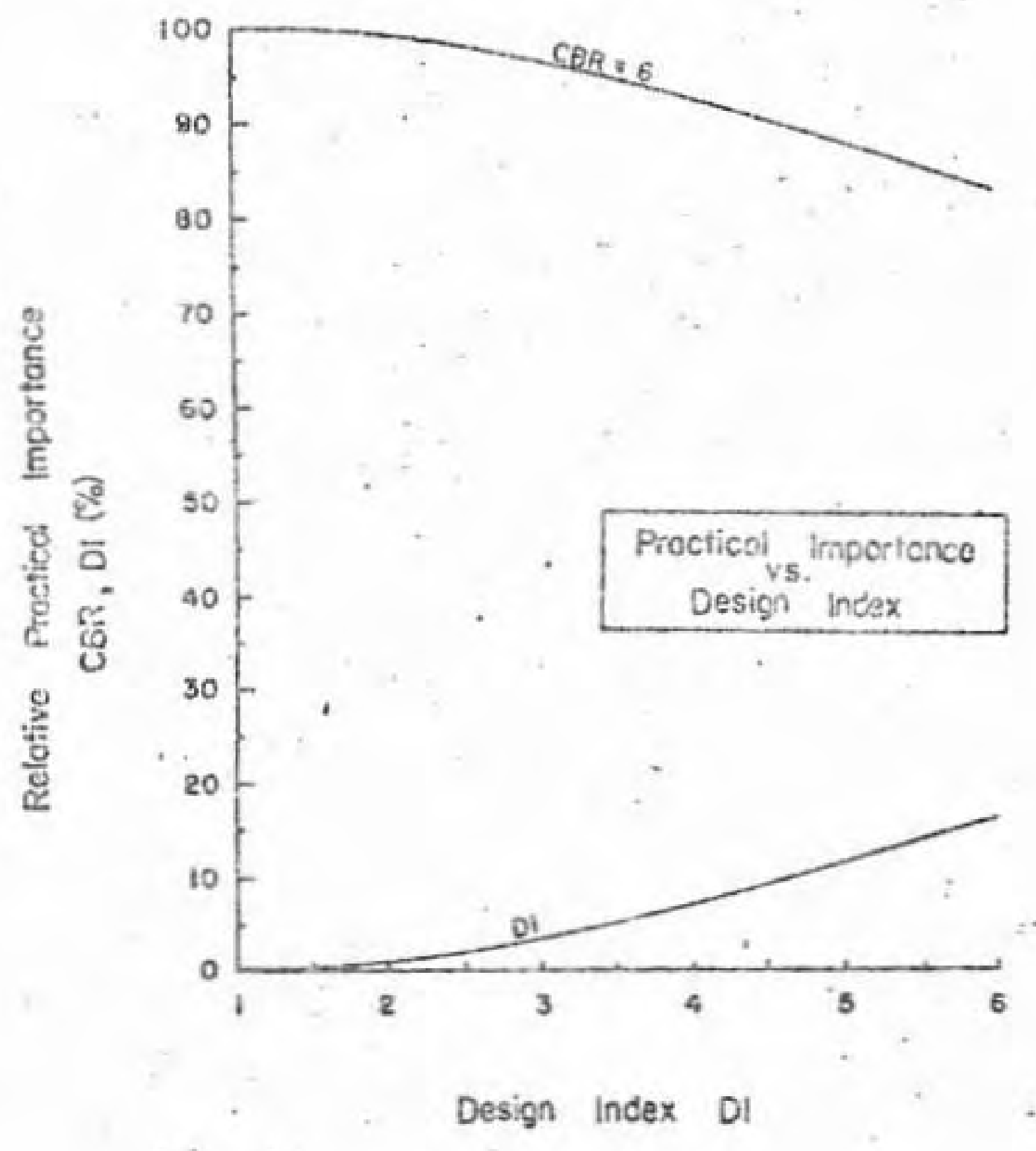

Figure 9. Relative Practical Importance of corps Flexible Design Promoters 
CORPS FLEXIBLE DESIGN

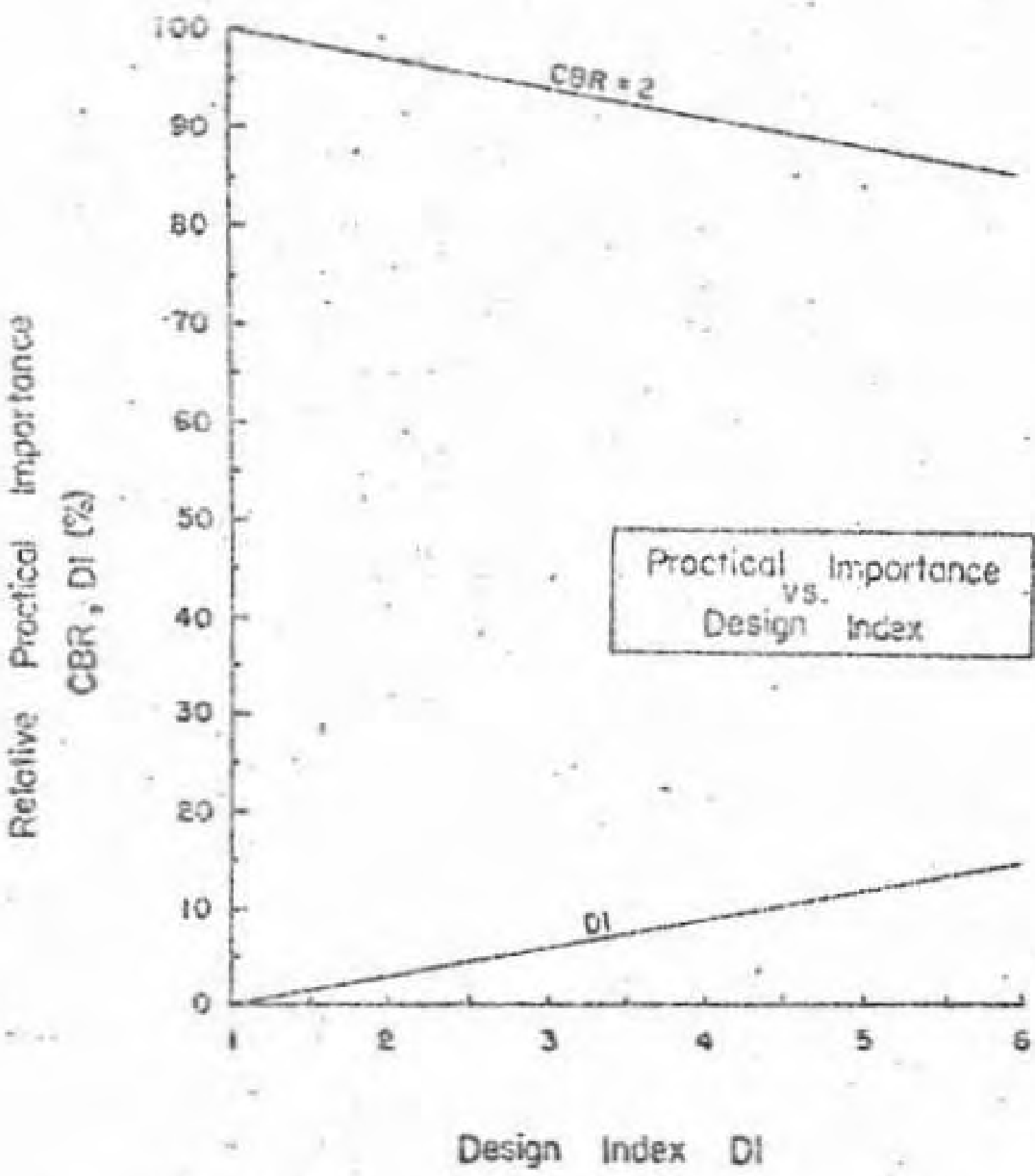

Figure 10. Relotive Proctical Imporiance of corps Flexibla Design Parometers 
CORPS FLEXIBLE OESIGN

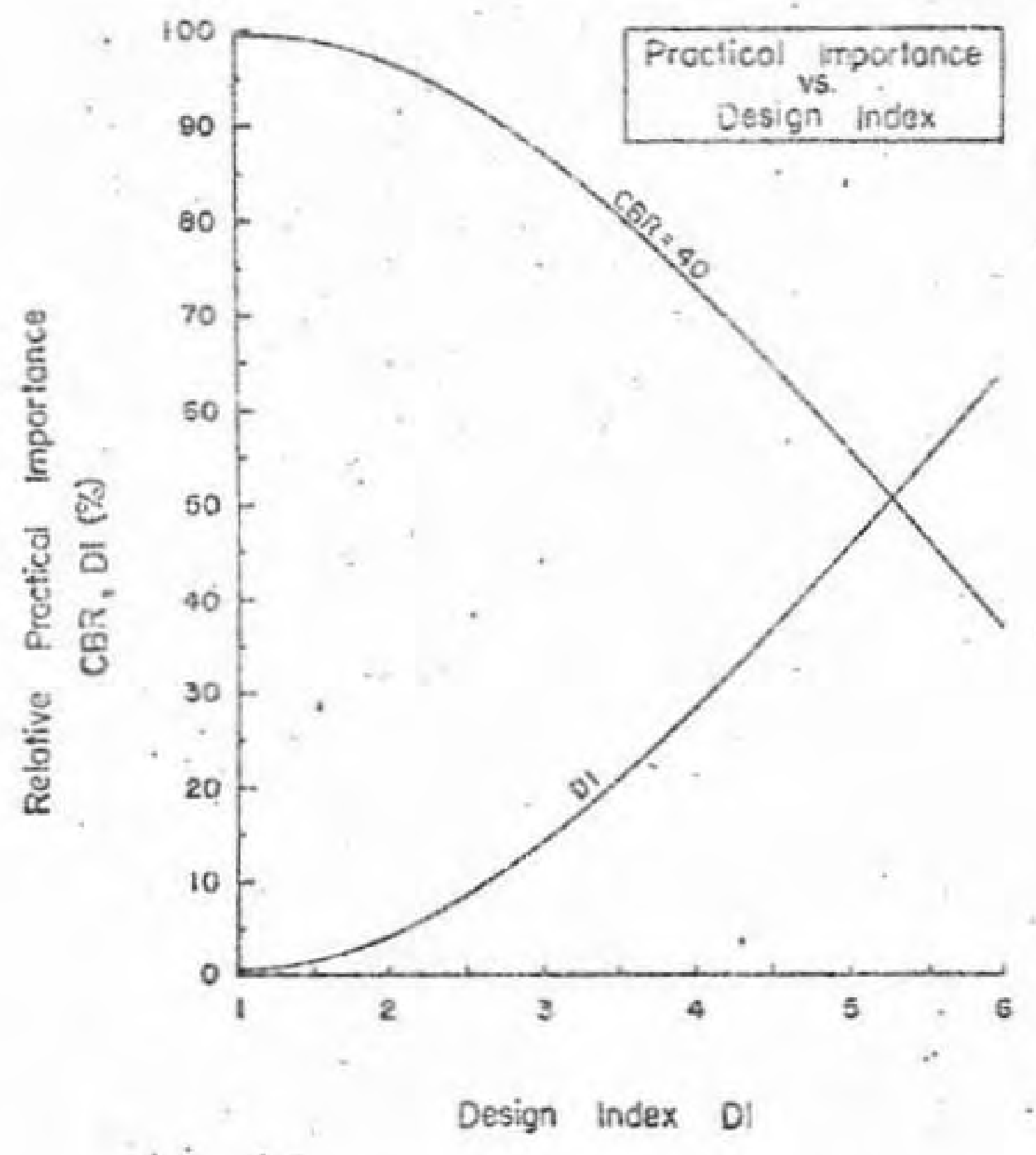

Figure 11. Reiative Proctical Imporionce of Corps Flexible Design Porometars 
CALIFORNIA STABILOMETER OESIGN

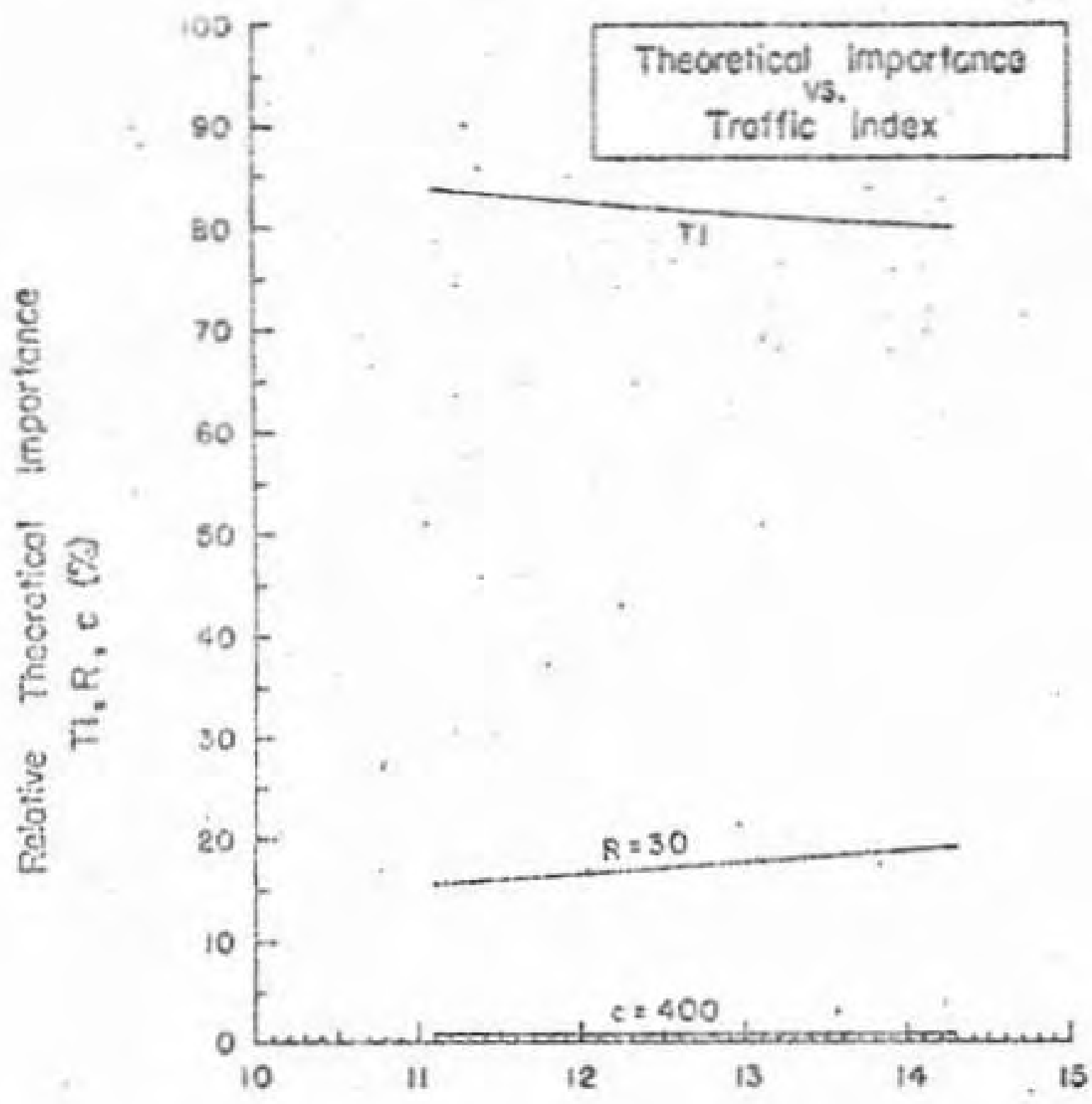

Traffic Index TI

Figure 12. Relotivo Theoretical Importcnce of Coilfornia Stobilometer Dasign Poromaters 
- CALIFORNIA STABILOMETER - DESION

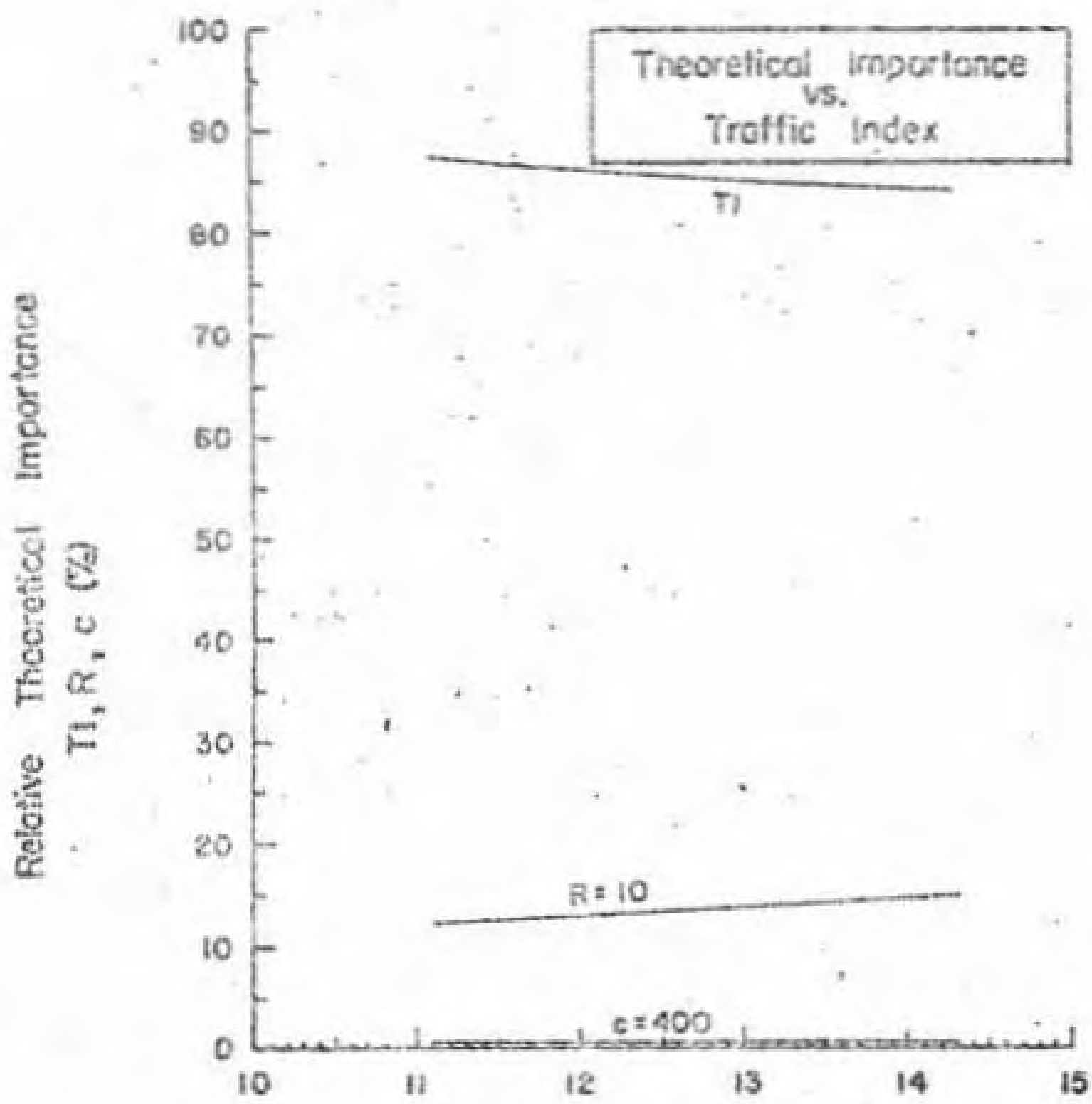

Tralfic tadex $\mathrm{TI}$

Figure 13. Ratolive Thecreticol impcrtence of Ceifornio Sicbilomeier Desiga Porenetors 


\section{CALIFORNIA STABILOMETER DESIGN}
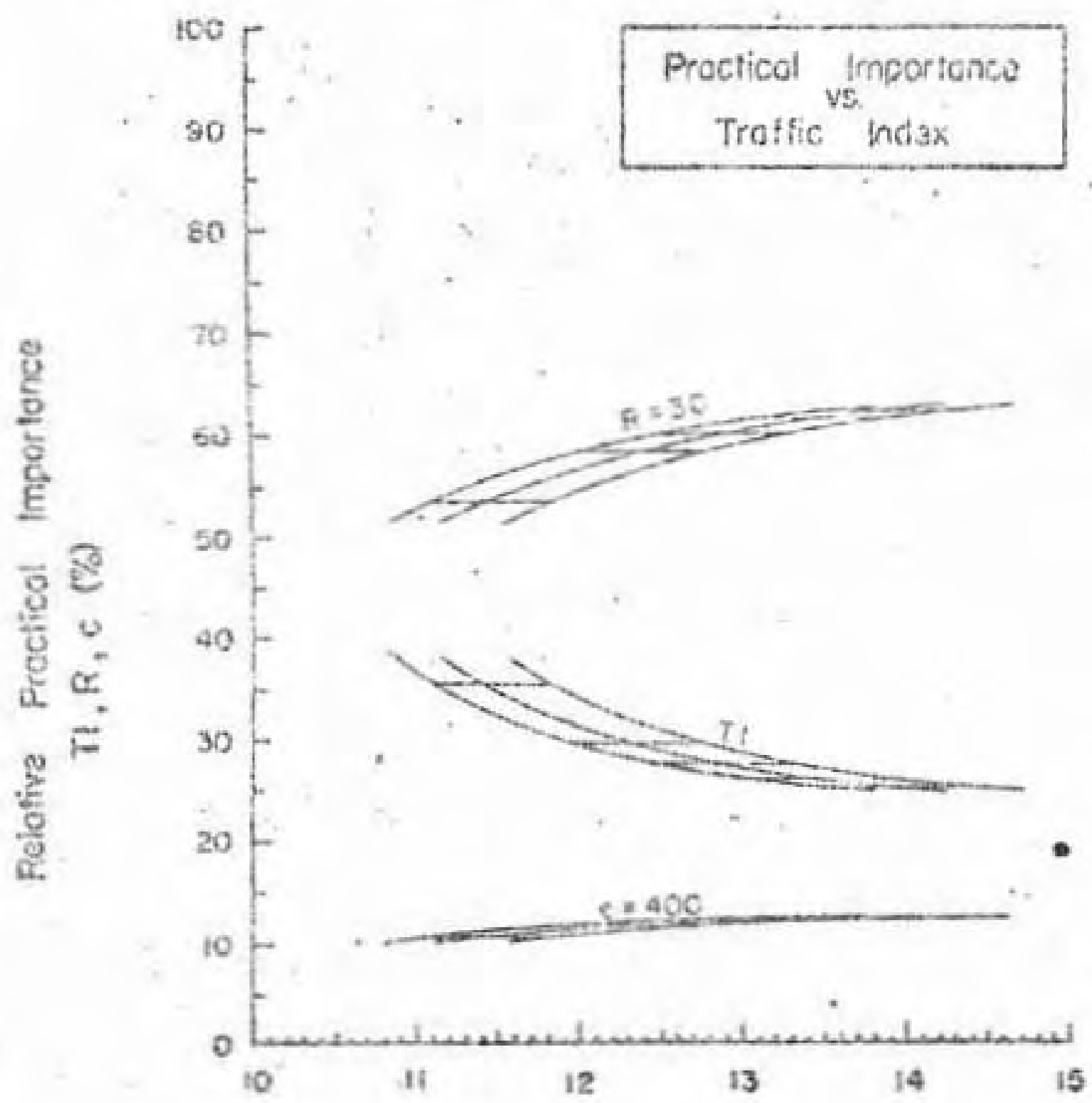

Troffic index TI

Figure 14. Reiative Procticol imporiance of Californio Stabilometer Design Poromaters. 
CALIFORIVIA STABHLNETER DESIGN

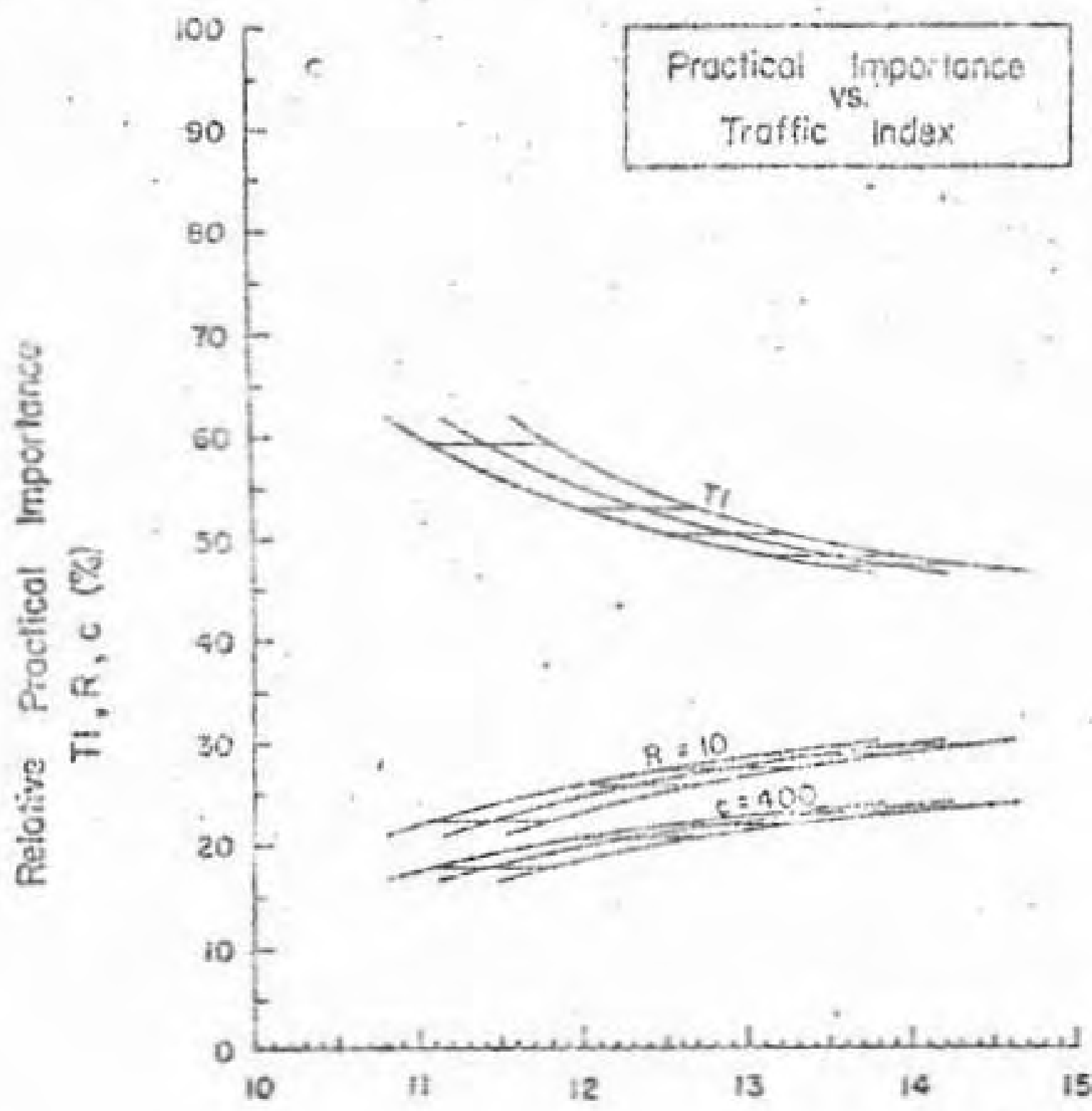

Troffic Indax $\mathrm{TI}$

Figare 15. Relotive Proctical Importunce of Colifornio Stobilometer Dasian Poremsiors 


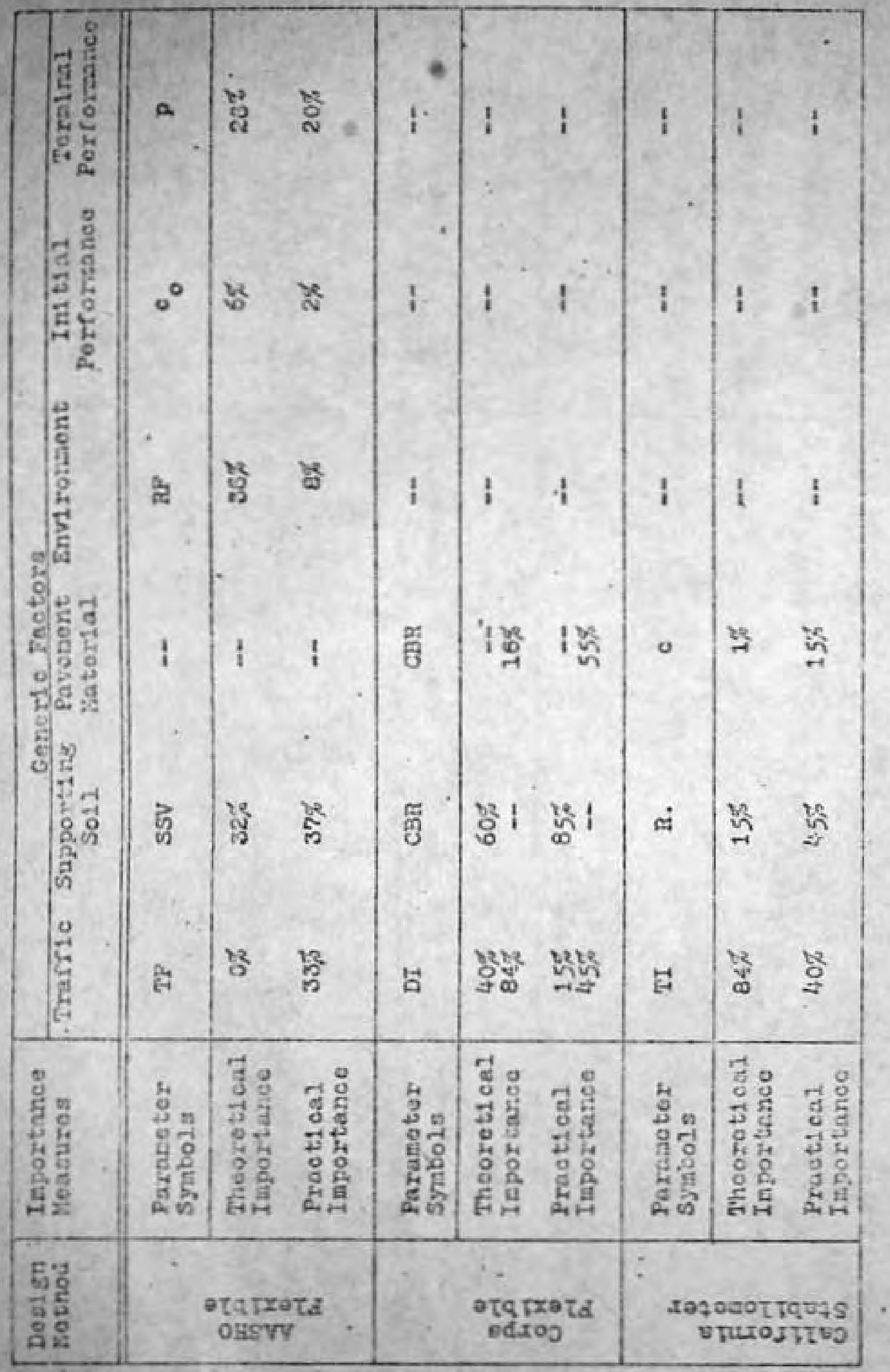

